УДК 378.31:330.322.3

\title{
ВЫПУСКНИКИ АСПИРАНТУРЫ И ИХ КОНКУРЕНТОСПООСОБНОСТЬ НА РЫНКЕ КВАЛИФИЦИРОВАННОГО ТРУДА
}

\author{
(C) 2012 г. О. М. Дудина
}

\section{Финансовый университет при Правительстве Российской Федерации, г. Москва}

Представлены результаты сочуиологического исследования конкурентоспособности выпускников аспирантуры - молодых кандидатов наук на рынке квалифицированного труда, проведенного на основе разработанной модели, включающей в себя индикаторы уровня конкурентоспособности и факторы, влияющие на нее. Определен уровень конкурентоспособности выпускников аспирантуры Финуниверситета - молодых кандидатов наук, который обусловлен иельым рядом факторов (личностных характеристик аспирантов, востребованностью на рынке труда и др.). Статья посвящена анализу факторов конкурентоспособности, обеспечиваемых вузом.

Ключевые слова: конкурентоспособность работника; конкурентоспособность выпускников аспирантуры - молодых кандидатов наук; уровень конкурентоспособности; факторы конкурентоспособности; конкурентные преимущества; рынок труда; кафедра; научная сочииализачия аспирантов; научный руководитель; включенность аспирантов в деятельность кафедры.

Here are the results of the sociological research of the postgraduate leavers'-young Ph.D.'s competitiveness in the modern skilled labour market, which was carried out being on the basis of the model including competition level indicators and factors, that can influence them. We have defined the level of competitiveness of Financial University postgraduate leavers - young Ph.D. The level of competitiveness is influenced by a number of factors such as personal features, labour market demand for them, etc. The article is devoted to the analysis of the factors of competitiveness that one provided by higher school.

Key words: employee's competitiveness; postgraduate leavers' - young Ph.D. 's competitiveness; competitiveness level; competitiveness factors; competitive advantages; labour market; subfaculty; socialization of the postgraduates in the field of science; scientific advisor; involvement of the postgraduates into the sub-faculty activity.

Актуальность исследования аспирантуры, ее эффективности как для выпуска конкурентоспособных специалистов, востребованных на рынке труда, так и для развития крупных институтов (в частности, науки и высшего образования), обусловлена проблемами модернизации общества и самих этих институтов.

Несмотря на трудности, связанные с экономическими реформами в российском обществе, массовое и длительное понижение жизненного уровня россиян и т. д., послевузовское образование в форме аспирантуры пользуется большой популярностью. Так, за период с 1995 г. по 2010 г. численность аспирантов выросла в 2,53 раза (с 62317 чел. в 1995 г. до 157437 чел. в 2010 г.), в особенности за счет социально-экономических специальностей.

Анализируя научные публикации по российской аспирантуре, можно выделить до 15 крупных противоречий ее развития. Наиболее важное из них заключается в следующем: российскому обществу необходима инфраструктура инновационного развития, в том числе использование результатов на- 
учных исследований и опытно-конструкторских разработок (НИР и ОКР) в экономике, в промышленности, в сфере услуг, с одной стороны, - и отсутствие их востребованности в реальном функционировании экономики (исключение составляют лишь некоторые наукоемкие отрасли). Мало востребованы и носители высокой квалификации - молодые кандидаты наук. В этих условиях становится понятной заинтересованность вузов в исследовании положения выпускников аспирантур - молодых кандидатов наук на рынке квалифицированного труда. Для изучения этих проблем в нашем вузе по решению ректората было проведено социологическое исследование «Эффективность аспирантуры Финансового университета при Правительства РФ и ее конкурентоспособность на рынке труда и образовательных услуг» ${ }^{1}$.

Конкурентоспособность работника, общности на рынке труда, как субъектов рыночных отношений, вызывает интерес со стороны представителей всех социально-гуманитарных наук. Он обусловлен переходом российского общества к рыночному устройству экономики. К настоящему времени сложились педагогический, психологический, социологический, экономический подходы (см., например, [2]) к анализу конкурентоспособности субъектов рыночных отношений. Однако, такая общность, как молодые кандидаты наук, их положение на рынке труда не исследовалось. Мало изучены и факторы их конкурентоспособности на рынке квалифицированного труда.

Для решения задач исследования мы включили в модель следующие, наиболее важные с нашей точки зрения блоки: 1) ресурсность; 2) профессионализм; 3) деловые и личные качества, необходимые для успешного выполнения профессиональных обязанностей; 4) соответствие требованиям потребителя (работодателя); 5) соответствие требованиям конкретного рабочего места; 6) готовность к конкурированию и торгу с ра- ботодателем за лучшие условия найма. Далее каждый блок конкретизировался через совокупность показателей более частного характера. Наличие или отсутствие этих свойств выступает фактором, влияющим на уровень конкурентоспособности. Отметим, что соответствие требованиям потребителя - работодателя может быть не только наличным, но и перспективным. Поэтому это свойство конкурентоспособности является относительным. Впрочем, мы поддерживаем точку зрения, согласно которой понятие «конкурентоспособность работника, специалиста на рынке труда» не является абсолютным, так как зависит от механизма, приводящего человеческую способность к производительному труду в функционирующее состояние. В модель были включены также факторы, влияющие на конкурентоспособность. Факторы конкурентоспособности молодых кандидатов наук - выпускников аспирантуры на рынке квалифицированного труда можно сгруппировать по масштабу социальной среды: 1) микро-факторы, то есть факторы, зависящие от личности аспиранта; 2) мезофакторы, которые зависят от работы самого вуза с аспирантами, его подразделений; взаимодействие аспиранта с ближайшей средой научной социализации: научным руководителем и кафедрой; 3) мега-факторы: ситуация и условия на рынке квалифицированного труда. Анализ полученных в ходе опроса данных проводился по полу, возрасту, курсу и форме обучения.

Результаты исследования показали, что уровень конкурентоспособности выпускников аспирантуры Финуниверситета - молодых кандидатов наук высокий и обусловлен целым рядом факторов (личностных характеристик аспирантов, востребованностью на рынке труда и др.). Отметим, что реальная защищаемость (с учетом защиты в течение первого года после окончания срока аспирантуры) составляет 54\%, это высокий показатель по сравнению со среднероссийским уровнем

1 Научный руководитель этого исследования - заслуженный деятель наук РФ, профессор Г. Г. Силласте, доктор философских наук, зав. кафедрой социологии Финансового университета при Правительстве РФ, соавтор инструментария. Менеджер проекта и ответственный исполнитель - доцент, к. филос. н., О. М. Дудина (разработка программы, соавтор инструментария, сбор анкет, научный отчет). Объект исследования: аспиранты, обучающиеся в стенах Финуниверситета. Сбор первичной социальной информации завершился в ноябре 2010 г., использовались методы раздаточного анкетирования и почтового опроса (рассылка анкет по электронной почте). Опрошено 179 человек, что составляет $41 \%$ от списочной численности аспирантов. 
защчищаемости диссертащий. Несколько слов о социальном портрете и «качестве» аспирантского сообщества Финуниверситета.

\section{1. Факторы, зависящие от наличных} характеристик аспирантского сообщества вуза

Среди наших аспирантов преобладают женщины (58\% по сравнению с $34 \%$ в среднем по России); соотношение полов обратное тому, как распределяются аспиранты по полу в стране в целом. Возрастная группа от 24 лет и старше составляет $2 / 3$ аспирантского сообщества (64\%); остальные - моложе. Иными словами, они достаточно социализированы и адаптированы. В браке (как в зарегистрированном, так и в незарегистрированном) состоят 21-22\% опрошенных. У $11 \%$ аспирантов есть дети.

Анализ данных исследования показывает, что, в первую очередь, аспирантское сообщество Финуниверситета отличается высоким уровнем ресурсности, трактуемой нами комплексно, как совокупность ресурсов любой природы, способствующих успешной защите и выходу на рынок престижного и высококвалифицированного труда (то есть обретению эксклюзивной конкурентоспособности). Исследователи из Нижегородского университета С. С. Балабанов и др. установили, что наиболее перспективными с точки зрения воспроизводства науки и высшего образования являются такие типы аспирантов, как «высокоресурсные» и «мотивированные» [1]. Наши аспиранты обладают лучшими характеристиками этих двух типов. Во-первых, они в достаточной мере подготовлены к научно-исследовательской деятельности в экономической аспирантуре: имеют высшее образование экономического профиля - $86,6 \%$; обучались на очном отделении $82,7 \%$; учились с отличной и хорошей успеваемостью в студенческие годы - 92,2\%; занимались научной работой в студенческие годы - 73,2\%\%. Многие свободно владеют иностранным языком. Они отличаются выраженными способностями к научной деятельности, мотивированы на учебу в аспирантуре и продолжение научной или научно-педагогической деятельности $(74,9 \%$ аспирантов полагают, что успеют защититься в срок; $32 \%$ выразили желание остаться на кафедре и стать преподавателем после защиты; 24\% полагают, что для них «кандидатская степень - это только начало научной карьеры; возьму курс на докторскую диссертацию»). Обладают хорошим социокультурным потенциалом (см. ниже анализ конкурентных преимуществ). С материальной стороны они хорошо обеспечены, имеют статус выше среднего. Уровень жизни семей аспирантов (либо родительских, либо своих) довольно высокий: от $87 \%$ до 90\% составляют те, кто определил его как «очень высокий», «высокий» и «средний». Различий в уровне жизни в зависимости от формы обучения нет. У них неплохое здоровье (в качестве трудности указали на «слабое здоровье» лишь единицы $6-7 \%)$.

Подавляющее большинство помимо учебы в аспирантуре также заняты на работе (их $84,4 \%$; не работают, а только учатся $12,8 \%)$.

Кроме того, наши аспиранты заняты преимущественно в финансово-экономической и банковской сфере (2/3 или $67 \%$ ответивших на вопрос о занятости). Иными словами, они востребованы на рынке труда по своим специальностям, и, следовательно, рабочие места в целом соответствуют профилю их образования. Это обстоятельство облегчает им работу над диссертацией. Неоднозначно можно оценить практически тотальную занятость аспирантов на работе. С одной стороны, она может быть источником информации для диссертационного исследования, с другой стороны, в наших исследованиях мы сталкивались с тем, что значительная часть выпускников Финуниверситета работают гораздо дольше, чем полагается, сильно устают, испытывают чувство эксплуатации, то есть несоответствия между своим вкладом в работу организации и его оплатой.

2. Уровень конкурентоспособности выпускников аспирантуры - молодых кандидатов наук на рынке высококвалифицированного труда

Для определения уровня конкурентоспособности мы использовали совокупность показателей. Конкурентоспособность выпускников аспирантуры Финуниверситета измерялась с помощью совокупности индикаторов: 1) конкурентные преимущества мо- 
лодого кандидата наук - выпускника Финуниверситета; 2) сравнение востребованности молодых кандидатов наук - выпускников Финуниверситета на российском и московском рынках высококвалифицированного труда; 3) сравнение уровней должностей, на которые могут рассчитывать при трудоустройстве молодые кандидаты наук и выпускники специалитета; 4) уровень должности, на которую могут рассчитывать молодые кандидаты наук при найме на работу по специальности а) в госучреждении, российской компании, b) в иностранной компании; 5) самооценка уровня своей конкурентоспособности на рынке

Наиболее обобщенное представление о нем дают ответы на вопрос: «Kaк бbl Bbl сегодня оценили уровень своей конкурентоспособности на рынке квалифицированного труда и престижных профессий?». Распределение ответов показывает, что общая самооценка аспирантами своего уровня конкурентоспособности на рынке высококвалифицированного труда такова (см. табл. 1).

Как видим, самооценка является достаточно высокой. Практически половина аспирантов считают себя высококонкурентоспо- собными специалистами. А если суммировать их ответы с ответами тех, кто выразил уверенность в возрастании конкурентоспособности за годы аспирантуры, то получится убедительная картина: от $71 \%$ до $77 \%$ опрошенных весьма удовлетворены уровнем своей конкурентоспособности. Отметим, что среди опрошенных вообще не оказалось тех, кто чувствует себя неконкурентоспособным: никто не выбрал вариант ответа «В данное время я неконкурентоспособен»; на недостаточный уровень конкурентоспособности указали 20,1\%. Субъективные оценки конкурентоспособности, данные аспирантами, подтверждаются и их объективными достижениями. Так, среди аспирантов преобладают те, кто занимают должности более высокие, чем рядовые специалисты: ведущих специалистов, руководителей среднего и высшего звена $(57,4 \%$ ответивших на этот вопрос аспирантов). Примерно треть - 33,5\% - находятся на должностях рядовых специалистов. Кроме того, большинство опрошенных (от $52 \%$ до $68 \%$ ) оценили размер, стабильность и престижность компаний, в которых они работают, по пятибалльной шкале на «4» и «5»². Иными словами, еще не завершив обучение

Таблица 1

Самооценка уровня своей конкурентоспособности на рынке квалифицированного труда и престижных профессий

\begin{tabular}{|l|c|c|c|}
\hline $\begin{array}{l}\text { Вопрос: Как бы Выз сегодня оценили уровень } \\
\text { своей конкурентоспособности на рынке ква- } \\
\text { лифицированного труда и престижных про- } \\
\text { фессий? }\end{array}$ & $\begin{array}{c}\text { Доля } \\
\text { ответивших } \\
\text { по выборке }\end{array}$ & $\begin{array}{c}\text { Доля отве- } \\
\text { тивших } \\
\text { среди } \\
\text { аспирантов- } \\
\text { очников }\end{array}$ & $\begin{array}{c}\text { Доля } \\
\text { ответивших } \\
\text { среди } \\
\text { аспирантов- } \\
\text { заочников }\end{array}$ \\
\hline $\begin{array}{l}\text { Считаю себя сейчас высоконкурентоспособ- } \\
\text { ным специалистом }\end{array}$ & 49,2 & 47,1 & 51,1 \\
\hline $\begin{array}{l}\text { За годы аспирантуры моя конкурентоспособ- } \\
\text { ность возросла, но еще недостаточная }\end{array}$ & 22,3 & 29,4 & 16,0 \\
\hline $\begin{array}{l}\text { Пока не чувствую себя достаточно } \\
\text { конкурентоспособным }\end{array}$ & 20,1 & 18,8 & 21,3 \\
\hline В данное время я неконкурентоспособен & 0,0 & 0,0 & 0,0 \\
\hline Затрудняюсь ответить & 5,6 & 2,4 & 8,5 \\
\hline
\end{tabular}

2 При этом с точки зрения размеров «5 баллов» означает, что компания крупная, а «1 балл» 一 небольшая. По критерию стабильности «5 баллов» означает очень стабильную компанию, а «1 балл» - совершенно нестабильную. По критерию престижности «5 баллов» - престижная компания, а «1 балл» - соответственно, совсем не престижная. 
в аспирантуре и пока не защитившись, наши аспиранты проявляют себя как достаточно конкурентоспособная группа на рынке высококвалифицированного труда.

Высокую оценку конкурентоспособности уместно дополнить данными о конкурентных преимуществах молодых кандидатов наук выпускников аспирантуры. Для их измерения в анкете была предложена номинальная шкала из 14 пунктов (см. таблицу ниже), включавших качества, связанные с профессионализмом; другие деловые и личные качества молодых кандидатов наук, а также ресурсы: «символический капитал» («признанная высокая престижность Финуниверситета») и «социальные капитал» («связи, знакомства с нужными людьми»). Ответы аспирантов впечатляют (см. табл. 2) . $^{3}$

Во-первых, в структуре конкурентных преимуществ в числе высоко- и среднезначимых конкурентных преимуществ молодых кандидатов-выпускников аспирантуры преобладают 3 качества, связанных с профессионализмом: «высокий уровень профессиональной подготовки», «профессиональная компетентность», «целеустремленность на профессиональном поприще». Особо значимыми оказались «интеллигентность, коммуникабельность» и «работоспособность, мобильность». Высоко ценятся аспирантами как конкурентное преимущество и два, так сказать, «внешнересурсных» качества: приобщенность к бренду Финуниверситета и «связи и знакомства с нужными людьми». Отметим, что опрошенными были признаны как менее значимые для конкурирования такие личные качества, которые связаны со способностями к процессам социального взаимодействия и сотрудничества, умением работать в группах, принимать социиальные и этические обязательства.

Во-вторых, самыми важными своими конкурентными преимуществами на рынке труда они рассматривают наличие такого ресурса (элемент «символического капитала»), как «признанная высокая престижность самого Финуниверситета» (69,8\%, 1 место), и такого качества, относящегося к профессионализму, как «высокий уровень профессиональной подготовки» (55,9\%, 2 место). Во вторую группу среднезначимых конкурентных преимуществ вошли профессиональная компетентность $(47,5 \%, 3$ место); самостоятельность, уверенность в себе (40,8\%, 4 место); интеллигентность, коммуникабельность (37,4\%, 5 место); целеустремленность на профессиональном поприще (35,2\%, 6 место); связи, знакомства с нужными людьми (33,0\%, 7-8 место); работоспособность, мобильность (33,0\%, 7-8 место). Остальные качества вошли в группу малозначимых конкурентных преимуществ.

В целом набор конкурентных преимуществ может только порадовать профессорско-преподавательский состав вуза и свидетельствует о том, что именно работа преподавателей с аспирантами вносит неоценимый вклад в формирование конкурентоспособного специалиста высшей квалификации.

Как мы видим, одно из самых сильных конкурентных преимуществ - «высокий уровень профессиональной подготовки» связано с деятельностью профессорско-преподавательского состава, с научной работой кафедр с аспирантами. Поэтому проанализируем данные, связанные с этим вопросом.

3. Факторы, которые зависят от самого вуза, его кафедр, подразделений; взаимодействие аспиранта с ближайшей средой научной социализации: научным руководителем и кафедрой

Анализ публикаций показывает, что эти факторы могут либо способствовать научноисследовательской деятельности аспирантов, либо сильно затруднять ее. Условия для работы аспирантов над диссертацией изучалась нами по нескольким показателям: 1) удовлетворенность условиями в целом (в том числе образовательным процессом); 2) сотрудничество с научным руководителем; 3) сотрудничество с кафедрой; 4) включенность в деятельность кафедры.

Как показывают данные опроса, аспи-

3 Частоту ответов аспирантов по пунктам предложенной шкалы можно распределить на 3 группы: 1) наиболее значимые конкурентные преимущества - частота ответов от $51,0 \%$ и выше, 2) среднезначимые конкурентные преимущества - частота ответов от $31,0 \%$ до $50,0 \% ; 3$ ) малозначимые конкурентные преимущества - частота ответов от $30,0 \%$ и ниже. 
Конкурентные преимущества молодого кандидата наук выпускника Финуниверситета

\begin{tabular}{|c|l|c|c|}
\hline №№ & \multicolumn{1}{|c|}{ Конкурентные преимущества } & Доля & Ранг \\
\hline 1 & $\begin{array}{l}\text { Признанная высокая престижность самого } \\
\text { Финуниверситета }\end{array}$ & 69,8 & 2 \\
\hline 2 & $\begin{array}{l}\text { Высокий уровень профессиональной } \\
\text { подготовки }\end{array}$ & 45,9 & 3 \\
\hline 3 & Профессиональная компетентность & 40,8 & 4 \\
\hline 4 & Самостоятельность, уверенность в себе & 37,4 & 5 \\
\hline 5 & Интеллигентность, коммуникабельность & 35,2 & 6 \\
\hline 6 & $\begin{array}{l}\text { Целеустремленность на профессиональном } \\
\text { поприще }\end{array}$ & 33,0 & $7-8$ \\
\hline 7 & Связи, знакомства с нужными людьми & 33,0 & $7-8$ \\
\hline 8 & Работоспособность, мобильность & 28,5 & 9 \\
\hline 9 & Инициативность, предприимчивость & 24,6 & 10 \\
\hline 10 & $\begin{array}{l}\text { Стремление к совершенствованию } \\
\text { в профессии }\end{array}$ & 20,1 & 11 \\
\hline 11 & Склонность к новаторству & 18,4 & 12 \\
\hline 12 & Ответственность профессионала & 16,8 & $13-14$ \\
\hline 13 & Умение работать в команде & 2,8 & $13-14$ \\
\hline 14 & Организаторские способности & 15 \\
\hline $\mathbf{1 5}$ & Отсутствие конкурентных преимуществ & & \\
\hline
\end{tabular}

ранты продемонстрировали высокий уровень удовлетворенности по всем мезоусловиям в целом, то есть преимущественно, организационным условиям, предоставляемыми Финуниверситетом для аспирантов (см. табл. 3). Ответы, свидетельствующие об удовлетворенности (сумма ответов «в полной мере» и «отчасти») составляет 81,5\% по сравнению с теми, кто выразил неудовлетворенность $(3,9 \%)$. С учетом критериев благополучного состояния дел по условию ${ }^{4}$ в число благополучных попали 8 из 13 условий, предложенных к оценке аспирантами в анкете: 1) получение консультаций преподавателей академии (84,3\% удовлетворенных по сравнению с 2,8\% неудовлетворенных - 1 место); 2) доступ к необходимой научной информации, работа БИК (76,3\% удовлетворенных по сравнению с 7,3\% удовлетворенных - 2 место); 3) сотрудничество с отделом аспирантуры (76,0\% удовлетворенных по сравнению с 17,3\% неудовлетворенных, менее $10 \%$ затруднившихся ответить - 3 место); 4) наличие научной литературы в библиотеке $(75,4 \%$ по сравнению с 7,3\% неудовлетворенных 4 место); 5) внимание ректората к проблемам аспирантуры (68,7\% по сравнению с 9,5\% неудовлетворенных, но при этом возросло

4 Можно предложить шкалу для оценки их удовлетворенности и считать, что те условия, удовлетворенность которыми выразили более 50\% опрошенных аспирантов и менее $10 \%$ неудовлетворенных - это условия вполне благополучные, не представляющие, как говорится, особых резервов улучшения. При этом около $10 \%$ и менее составляют те, кто затруднился ответить, то есть они хорошо понимают и информированы о том, что они оценивают. 
количество «затруднившихся ответить» 5 место); 6) сотрудничество с кафедральным куратором аспирантуры (67,1\% удовлетворенных по сравнению с 7,8 \% неудовлетворенных - 6 место); 7) участие в российских конференциях (55,9\% удовлетворенных по сравнению с 8,4\% неудовлетворенных 7 место); 8) условия проживания в общежитии. По остальным 5 условиям число удовлетворенных тоже превосходит тех, кто испытывает неудовлетворенность, но не столь убедительно. Эти условия представляют собой определенный резерв для совершенствования и принятия управленческих решений, помощи аспирантам, возможно - со стороны ректората, а также кафедр. К ним относятся: публикации своих научных работ; участие в исследовательских проектах; апробация своих научных разработок на практике; участие в международных конференциях; возможностью публикации в «Вестнике Финуниверситета»).

На основе анализа литературы, бесед с аспирантами, которые мы проводили как неформализованные интервью (например, при рассылке анкет и мотивировании заполнить их), а также и с преподавателями нашего вуза, мы разработали целый комплекс предложений, которые, по нашему мнению, могут улучшить в настоящее время деятельность аспирантуры. Поддержка этих предложений со стороны аспирантов представлена в таблице 3.

Итак, мы видим ${ }^{5}$, что наиболее значимы-

Таблица 3

\section{Предложения аспирантов по совершенствованию деятельности аспирантуры Финуниверситета}

\begin{tabular}{|c|c|c|}
\hline Ранг & $\begin{array}{c}\text { Вопрос: Что Вы посоветовали бы предпринять для повышения эффектив } \\
\text { обучения в аспирантуре Финуниверситета? }\end{array}$ & ости \\
\hline 1 & $\begin{array}{l}\text { Улучшить информирование аспирантов о проводимых конференциях в } \\
\text { Москве и России }\end{array}$ & 69,8 \\
\hline 2 & Использовать стажировки в зарубежные вузы & 52,5 \\
\hline 3 & Чаще проводить мастер-классы для аспирантов & 50,3 \\
\hline 4 & Оплачивать участие аспирантов в зарубежных конференциях & 40,8 \\
\hline 5 & $\begin{array}{l}\text { Более широко практиковать проведение Круглых столов и конференций } \\
\text { для аспирантов }\end{array}$ & 38,0 \\
\hline 6 & Повысить размер стипендии & 34,1 \\
\hline 7 & $\begin{array}{l}\text { Улучшить информирование организаций, в которые обращаются аспиран- } \\
\text { ты для сбора информации, о деятельности аспирантуры Финуниверситета }\end{array}$ & 30,2 \\
\hline 8 & Увеличить доплату на покупку научной литературы & 29,1 \\
\hline 9 & $\begin{array}{l}\text { Повысить информированность самих преподавателей об актуальных на- } \\
\text { правлениях в профильной науке }\end{array}$ & 24,0 \\
\hline 10 & $\begin{array}{l}\text { Информировать студентов-старшекурсников о возможностях целевой ас- } \\
\text { пирантуры }\end{array}$ & 20,7 \\
\hline 11 & Строже контролировать выполнение данных заданий & 14,5 \\
\hline 12 & $\begin{array}{l}\text { Установить дни расписания преподавания всех специальных дисциплин, } \\
\text { т. к. самим их качественно не освоить }\end{array}$ & 12,8 \\
\hline
\end{tabular}

5 Для оценки степени значимости этих предложений для самих аспирантов мы воспользуемся следующей шкалой: 1) предложения, которые были отмечены более, чем 50\% опрошенных, будем рассматривать как наиболее значимые; 2) предложения, которые нашли поддержку от 30\% до 49\% аспирантов - среднезначимыми; 3 ) предложения, которые были отмечены менее чем $29 \%$ опрошенных, будем рассматривать как малозначимые для группы в целом, но не лишенные смысла для определенной части аспирантского состава. 
ми для аспирантов являются сейчас такие предложения, как «Улучшить информирование аспирантов о проводимых конференциях в Москве и России» (69,8\%, 1 место); «Использовать стажировки в зарубежные вузы» (52,5\%, 2 место); «Чаще проводить мастерклассы для аспирантов» (50,3\%, 3 место). Зарубежные стажировки, правда, выглядят утопичным предложением, учитывая, что аспиранты работают, и заняты в сфере бизнеса, так что стажировки хороши, конечно, но для определенного контингента аспирантов например, для неработающих.

Наши наблюдения за аспирантами, выходящими уже на финишную прямую и занятыми подготовкой диссертации и автореферата к обсуждению, свидетельствуют о том, что, конечно, нужнны мастер-классы для аспирантов, направленные на освоение связей между теоретическими и эмпирически данными, осмысление того, какие методологические принципь они использовали и т. д., формулировку новизныл, положений, выносимых на заuзиту. Именно по этим моментам эксперты в диссоветах частенько делают замечания, несмотря на кропотливый труд научных руководителей. Сказывается «заочный» характер аспирантуры.

Отдельного внимания заслуживают также те проблемные ситуации, противоречия - социальные и гносеологические - которые сложслись в практике и дисииплине, по которой они зашчищаются, и на решение которых направлено их исследование. Этого требуют также и ужесточающиеся требования ВАКа.

Следующая группа предложений по частоте отметивших являются среднезначимьми. К ним относятся такие, как «Оплачивать участие аспирантов в зарубежных конференциях» (40,8\%, 4 место); «Более широко практиковать проведение Круглых столов и конференций для аспирантов» (40,8\%, 5 место); «Повысить размер стипендии» $(34,1 \%$, 6 место); «Улучшить информирование организаций, в которые обращаются аспиранты для сбора информации, о деятельности аспирантуры Финуниверситета» (30,2\%, 6 место).

Предложение об организации кругльхх столов для того, чтобы аспиранты проходили своеобразный тренинг публичных выступлений и участия в научных дискуссиях, нам кажется весьма целесообразным. По крайней мере, об этом свидетельствует практика аспирантской конференции «Экономическая социология: проблемы, парадигмы, противоречия», проводимой на нашей кафедре: в гости к нам на эту конференцию приходят и выступают аспиранты экономических кафедр нашего вуза и других вузов, а не только социологи.

Видимо, эти предложения имеет смысл рассмотреть в организационно-управленческом плане, но, так сказать, адресно, иуелевым способом. Так, в отличие от ситуации, которая описывается в социологической литературе, когда исследователи выделяют группу аспирантов «умных, но бедных», в нашем вузе такие проблемы имеет лишь очень небольшая часть аспирантов: 7-8\%, которые ответили, что живут «ниже среднего» а остальные - на «среднем» и «высоком» уровне. Поэтому, возможно, им следует каким-либо образом помогать материально.

Важно также и предложение об информировании организаций, в которые обращаются аспиранты для сбора информации о деятельности аспирантуры Финуниверситета. Проблема недостаточности эмпирической информации в диссертациях часто обсуждается на совещаниях по повышению качества и актуальности диссертационных исследований. Поэтому, вероятно, можно было бы предложить как пункт совместной деятельности Отдела аспирантуры и Отдела маркетинга Финуниверситета - «улучшить информирование организаций, в которые обрашаются аспиранты для сбора информачии, о деятельности аспирантуры Финуниверсиmета» (аспиранты, в частности, просили об оформлении специальных писем в организации).

Отрадно, что малозначимым оказалось предложение «повысить информированность самих преподавателей об актуальных направлениях в профильной науке» - на это указали только 24,0\% опрошенных аспирантов.

Аспиранты-очники более чувствительны оказались к таким предложениям, как «повысить размер стипендий», и «использовать стажировки в зарубежные вузы» (соответственно, 58,8\% и 64,7\%).

Аспиранты-заочники более чувствительны к предложениям, связанным с расшире- 
нием возможностей выступлений по теме диссертации: несколько выше чем в среднем по выборке, они отметили необходимость «более широко практиковать проведение круглых столов и конференций для аспирантов» - 44,7\% по сравнению с 38,0\% по выборке; а также «улучшить информирование аспирантов о проводимых конференциях в Москве и России» - 74,5\% (в среднем по выборке 69,8\%).

Особых предпочтений по предложениям в зависимости от года обучения выявлено не было.

Таким образом, результаты проведенного исследования и сравнения с положением дел в других вузах, показывают, что, несмотря на общие негативные проблемы развития российской аспирантуры, каждый вуз благодаря социологическим исследованиям своего аспирантского сообщества может выявить те факторы, которые зависят именно от данно- го вуза и которые можно регулировать на его уровне.

По-видимому, немаловажным подспорьем при разработке управленческих решений, направленных на повышение конкурентоспособности молодых кандидатов наук - выпускников аспирантуры на рынке труда, может служить социологический мониторинг.

\section{Литерат ура}

1. Балабанов С. С., Бедный Б. И., Козлов E. В., Максимов Г. А. Многомерная типология аспирантов. // Социологический журнал. - 2003. - №3.

2. Кутейницына Т. Г. Конкурентоспособность специалиста: критическое прочтение отечественных публикаций. // Современные исследования социальных проблем. 2011. - T. 8. - №4.

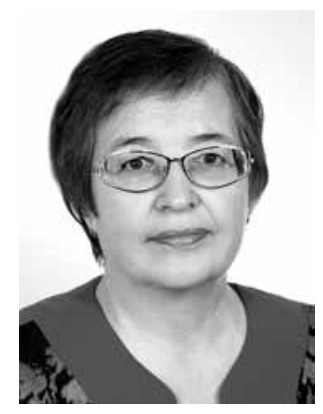

Ольга Мухаметшевна Дудина - кандидат философских наук, старший научный сотрудник, доцент Финансового университета при Правительстве Российской Федерации.

Olga Mukhametshiyevna Dudina - Ph.D., Candidate of Philosophy, senior research assistant, docent at the Financial University under the Government of the Russian Federation. 